\title{
Analysis on Contemporary Value Orientation of Tao Xingzhi's Education Concept
}

\author{
Chunli Wang \\ Sanmenxia Polytechnic, Sanmenxia, 472000, China
}

Keywords: Tao Xinzhi. Education concept. Value orientation. Mass Education

\begin{abstract}
In the education work, there are a lot of factors influencing the development of education work, in which the education concept decides the overall trend of the education work and the teaching method. So it can be seen that an advanced education concept is an inseparable spiritual leader in the contemporary education and teaching. In this paper, the three important contents of Tao Xingzhi's education concept are briefly analyzed first, and then the contemporary value of his education concept is discussed.
\end{abstract}

\section{Introduction}

Tao Xinzhi, born at the end of the 19th century, experienced the great social change. Always living at the bottom level of the society, he weathered the wars and was sympathetic to the masses for their hard life, so he was determined to become a pioneer to change the backwardness of China. After many times' personal practice and hard working, he finally form a unique education concept, and guided the development of education cause and the reform of teaching work of China for nearly one century. The education value orientation means the value trend to carry out education, which guides the education to progress toward the correct direction. At present, it is an issue that must be highly emphasized on what is the value orientation of Tao Xingzhi's concept, how to use the education concept of Tao Xingzhi to deepen the education reform of China and promote the further development of education cause of China, and also the key point for research in this paper.

Tao Xingzhi, an age pioneer in of education cause of China, was devoted to researching the educating theory and engaging in teaching practice in his whole life, and his education concept is the systematic knowledge on the significance and function of education work to the social development and human progress formed in his learning and practice process and his education has always been guiding the reform and development of Chinese education cause. To sum up, the education concept of Tao Xingzhi mainly includes the following:

\section{Life is education and society is the school}

Tao Xingzhi thought that life is the best education and he rejected the regarding of education as life. He thought that the best way to cultivate talents is to place the talents in the overall social environment and make them blend in the society and he also believed that everything in life could be the teacher to guide students for progress; on the contrary, if education was regarded as life, the students could obtain knowledge only from school, just like the caged birds which would never have opportunity to fly in the sky. Life is education, life is changing at any time and is endowed with different education significances. Life is everywhere, so is education. The whole human society is the place of life, and also the place of education. He thought that the society is a natural school, including everything and is a knowledge library that cannot be learnt completely by any person in his life. He held the idea that in the school of running, schools should not be blind, but must combine the teaching with the actual social condition and open the school needed by the mass. Only by regarding the society as the class can the education contents be enriched maximally. The life lead in the society is consistent with the knowledge learnt from life. Only by combining teaching work with the actual life can he education role be really played. Education is closely related with life, life can improve education, and meanwhile, education will act on life, reconstruct the society and nature. 


\section{Promote mass education thought and popularize teaching work comprehensively}

The mass education thought is the theoretical experience formed by Tao Xingzhi when working in the Chinese Mass Education Promotion Society. Tao Xingzhi thought that the purpose of mass education is to eliminate illiteracy and cultivate the civic awareness of the nationals. Improving the cultural quality of the nationals cannot only increase the nationals' identity to the history and culture of our country, enhance the national unity, but can also bring more employment opportunities to each person and improve the individual living ability. Tao Xingzhi thought that mass education and the comprehensive popularization of education work can make more people know about the meanings of rights, democracy, obligations and freedom, enlighten the masses' consciousness of democracy, and this is a key step to march forward democracy and republicanism. As the pioneering of education popularization, mass education must achieve the best effect within the shortest time. Tao Xingzhi realized the importance of education to the common people earlier, during this period, his education gradually entered the circle of common people, and he transformed the key point of his teaching to the common people. However, Tao Xingzhi did not have a deep analysis on the current situation of Chinese education and the mass education activity was mainly dominated by the officials and intellectuals, causing that the common education activity was still mainly aimed at the common people in the towns, and the incentive of the common people to participate in the teaching activity was not fully motivated. However, through this practice experience, he accumulated rich teaching experience. Although Tao Xingzhi advocated the saving of nation through education, when promoting the thought of mass education, he did not involve in too many political connotation, and paid more attention to the cultivation of people, which was greatly different from the thought of "self-cultivation, family management, nation governance and world peace" in the mass education thought advocated by Yan Yangchu, and this was the reason for the difference of thoughts of Tao Xingzhi and Yan Yangchu and for them to go their own way. In general, the mass education concept of Tao Xingzhi still emphasized the development of common people themselves, but not the education needed in the times of war. He expected to help improve the national quality through mass education and help the Chinese nation constantly strive to become stronger.

\section{Promote independent learning and oppose "spoon-feeding" education}

The "spoon-feeding” education was invented by the Soviet Union educator Kaiipob, which was abandoned by the Soviet Union people once when it appeared. As the education system in China was imperfect at that time, the failure of Kaiipob was picked up in China. Just as its name implies, "spoon-feeding" education means to infuse the knowledge to students forcefully, no matter whether the students can understand, as long as the purpose of mechanical memorizing can be achieved. In terms of the advantages of "spoon-feeding" education, it is helpful for the sudden examination, and can make students accumulate a great amount of knowledge within a short time, but after examination, the students will forget the knowledge; for the disadvantages, the infused education cause that the students lose creation and their understanding to the knowledge is also superficial without deep understanding. Tao Xingzhi opposed this education mode extremely, once in a speech, he picked out a big cock prepared from a case, when the audiences did not understand why he did so, he picked out a handful of price from his pocket, and press the head of the cock to force it to peck, but the cock never ate it. So he asked his assistant to tear the mouth of the cock, and filled the rice to the cock's mouse, but the cock always strived to struggle without eating the rice. Finally, he placed the cock on the table, and got away from the surrounding people, soon, the cock ate the rice at its own discretion. At this moment, Tao Xingzhi stood on the platform and began an impressive speech, "education is like feeding the cock, if a teacher forces the students to learn just like forcing the cock to peck the rice, the students are unwilling to learn extremely. Even if they learn as required, they will not digest the knowledge, and will return it to the teacher soon. However, if the students are released just like the cock to learn independently and make full of their subjective initiative, their learning effect and efficiency must be higher." He extremely advocated the change of "spoon-feeding" education, and proposed students to learn independently and stimulate the students' potential, and this is an important manifestation in his teaching concept. 


\section{Contemporary value orientation of Tao Xingzhi's education concept}

Tao Xingzhi was devoted to teaching for decades, and his education concept had a far-reaching influence on the later generation. By far, Mr. Tao Xinzhi has been dead for 67 years, but his education concepts like "life is education", "society is school", "mass education”, "village education" and "integration of teaching and learning" still provide support for the development of Chinese education cause, and most of the value orientations of development of education cause are based on his education concepts.

\section{To guide teaching work, teaching must be concerned}

Tao Xingzhi proposed the teaching concepts like "life is education" and "society is school”, which fully reflect the characteristics of practical teaching. Knowledge is from life and changes life. Tao Xingzhi believed that what the school gives students is just the systematic knowledge frame, while the specific contents and experience in the frame should be filled in by the students themselves, which could not be imparted by teachers. Different individuals have great differences for the perception to life and understanding to knowledge. Therefore, he advocated the placing of teaching work in social life and believed that society and school are together, life is inseparable from life, and education cannot get away from the practice, let alone violating the normal life of people. When promoting the village education, he strictly implemented this thought, and asked teachers and students to carry out education activity centered on life, the teachers and students make efforts to construct the school and let students liberate their hands, brain and mouth in social practice, reconstruct the students' traditional thinking and ideology. He said, "education work is not to cultivate the bookworms who could not only recite the classics, but to cultivate the talents for social construction, while for the cultivation of talents, it is infeasible only to speak but not practice and teaching must be combined with practice.” This is the prototype of practical teaching in the new times, laying a solid theoretical foundation for the comprehensive reform of modern Chinese education toward the practical teaching. At present, the importance of education is more and more highlighted, and the imprisonment of traditional teaching method to the students' ability has seriously hindered the social, economic and political construction. In consideration of this, the current education work must be reformed comprehensively. Practical education is evolved from the teaching concepts of Tao Xingzhi like "life is education”, "society is school” and "experimentalism” and gradually developed, guiding the value orientation of Chinese education cause in the new times.

Tao Xinzhi was born in the old China under the ruling of the corrupted government. Born in poor, he knew that it was not easy to receive education when he was very young. Besides, as China was in the times of war turbulence, he experienced the bumpy road of receiving education. He expected to save China through education cause, while the root to save the nation was to improve the quality of nationals. In consideration of this, he transformed the key point of education work to the improving of the quality of most of the urban common people and rural farmers. Just like the saying goes "the strengthening of a nation lies in the nationals, the strengthening of nationals lies in quality and the strengthening of quality lies in education.” To constantly strive to become stronger and take the road of democracy and republicanism, China must do the education work well, particularly the whole-people education. In the long-term education, Tao Xingzhi recognized the current situation of Chinese education and the key to save the nation, that was to comprehensively popularize the education work, which was reflected in his teaching concepts like "mass education" and "rural education". Currently, with the coming of the times of knowledge economy, talents have come the base for all competition, and those who own more talents will have more rights to speak in development. In the new period, it is very urgent to comprehensively popularize the education cause of China, and whole-people education must be required, and this is also an important manifestation that Tao Xingzhi's teaching concepts guide the education cause value orientation of China.

\section{To guide the current teaching, "teaching, learning and practice" must be integrated}

In the traditional teaching method, teachers mainly adopt the "spoon-feeding" education, and infuse all knowledge to students, no matter whether the students can understand it. By contrast to the teaching concept of "integration of teaching, learning and practice", this teaching method only 
emphasizes "teaching" partially, and the "teaching" is not the effective "teaching", but to only complete the work. After returning to China against the current situation of "mechanical teaching and learning", Tao Xingzhi proposed that "the responsibility of a teacher is not to teach the students, but to teach them to learn,... and should lie in learning but not teaching". He opposed the teaching method of separating teaching, learning and practice but advocated the integration of teaching, learning and practice. Teachers should be based on practice and should teach students while learning by themselves students should be based on "practice" and learn while practicing”. Learning is not only to use brain, but also to practice, only the combination of brain and hand is the best learning method. Tao Xingzhi's teaching concept "integration of teaching, learning and practice" has a far-reaching influence. Up to now, it is still the main teaching thought guiding the comprehensive development of teaching of China. In the new times, Tao Xingzhi's teaching concept "integration of teaching, learning and practice” plays an active and great role for liberating the students and teachers' thought, improving teaching efficiency and quality and stimulating students for learning, being the main value concept to guide the development of education work of China.

\section{Conclusion}

As a pioneer in of education cause, Tao Xingzhi made great contribution for the starting and development of modern education of China. Till now, his teaching concepts are still the main value orientation in the education work of China. In the process of developing the Chinese education, we must research Tao Xingzhi's education concepts meticulously, combine them with the characteristics of the times and the current situation of education, so as to deepen the reform of Chinese education cause and further promote the development of education.

\section{References}

[1] Zhang Yemao, Practicing of Tao Xingzhi's Education Concepts by Hualian Educators-One of the Running Characteristics of Private Hualain University [C].// collected papers of seminar on carrying out Planning Outline and promoting the school running by educators, 2010: 128-134

[2] Du Qinhong, Historical and Realistic Harmony-Application of Tao Xingzhi’s Life Education Concepts in History Teaching of Senior Middle School [J], Examination Weekly, 2013, (36): 124-125

[3] Wang Li, Li Ming, Awakening Heart and Shaping Personality-Practicing of Tao Xingzhi's Education Concepts in Education [J], Middle School Student Guide (Teaching and Research Weekly), $2012(20)$.

[4] Xu Ping, Innovation and Development-Discussion on Innovative Teaching of Narrow Vision under the guidance of Tao Xingzhi's Education Thought

[5] Zhu Benhai, Emphasizing Life Education and Comprehensively Improving Scientific Literacy Comprehensively- Several Measures to Practice Tao Xingzhi's Life Education Concept, [J], New Curriculum (teacher edition), 2012 (12): 6-7

[6] Wang Xiaoxian, Yu Xiaoxiao, Adhering to Talents Cultivation Concept and Enhancing Characteristic Education-Application of Tao Xingzhi's Thought of "Six Lineation" in Characteristics Basketball Event [J], Road to Talents, 2013 (20): 60-60

[7] Wu Fei, Effective Construction of College English Class Teaching of Higher Art Institutes based on the Tao Xingzhi’s Education Thought of “Little Teacher System” [J], Science and Teaching Guide, 2013, (7): 19-20

[8] Ran Xia, Labor Promoting Self-growth, Education Perfecting Personality Cultivation-Restricted View on Tao Xingzhi's Life Education Thought [C]. // collected papers of seminar on Tao Xingzhi's education thought and the development of western rural education, 2010: 20-23 